\title{
Creatively Prototyping the Future High Street
}

Abstract - This paper gives a voice to a range of community and individual stakeholders who would not generally be heard in the conventional town planning process. We present a methodological technique, described as creative prototyping, that has at its heart, the capability to enable full stakeholder inclusivity into the future imagining of the smart city. Actively involving these individuals and community representatives in the research process enables deeper understanding of how technology and people can interact productively to create smart cities that are socially inclusive while still being commercially relevant. The research data for this paper is drawn from the findings of a workshop conducted by the authors that utilised Science Fiction Prototyping and Lego Serious Play. This research activity was driven by questions focusing upon the current complex interplay and tensions of technology and the UK's physical high street. We first explore these issues theoretically in previous literature and then drawn upon this review to analyse the outcomes of the workshop. Three themes emerge from this analysis that have operational and strategic relevance to the development of future high streets; the importance of ever present but invisible technology, the forefronting of people in the smart city and the need for wide-ranging stakeholder input and participation into planning. The findings also illustrate that not all future imaginings of the retail high street are immediately practical or realistically applicable. However, in examining the many issues facing the current high street and in negotiating the multiplicity of voices with their competing demands and expectations we offer the conclusion that the future smart city must become a place of truly shared sociality rather than just mere proximity, customised convenience or a concentration point for multiple forms of entertainment.

\section{Introduction - inclusive operational planning for the smart city}

There has been much debate regarding the meanings of the concept of smart cities. In a recently commissioned report by the UK government it is claimed that there is no explicit or agreed terminology for a smart city. However, in the absence of firm definitions the UKGov 2013 report offers the parameters that a smart city must be more 'liveable', 'resilient to change' and 'should enable every citizen to engage with all the services on offer, public as well as private, in a way best suited to his or her needs' (UKGov 2013). The report further argues that a smart city should bring together infrastructures, the social capital of local skills, communities, institutions, and technologies for sustainable economic growth. According to Shapiro (2006) it is extremely important to consider the integrative abilities of digital technologies throughout urban environments and how the application of these technologies can improve the overall general quality of life including how people work, travel, play and live. We take up the challenge offered by Shapiro through 'engagement work' that is articulated in research that brings together a range of community and individual stakeholders who would not generally have a voice in conventional town planning processes. The active involvement of these individuals in the research process enables deeper understanding of how technology and people can be combine constructively to create smart cities that are socially inclusive and retain their relevance in a commercial and retail sense. Our approach is informed by the concept of the "creative consumer" (Pehlivan et. al, 2007; Berthon et. al., 2007); consumers who generally have no 
formal interaction with the organisation yet through creative use of new technologies can "modify a product (or service) and reposition it to achieve new goals" (Pehlivan et. al., 2007). The focus of this paper is to examine recent policy and commercial developments in the UK retail sector and whether the incorporation of stakeholder voices can deliver any form of resolution to the situation currently facing the UK high street. The high street, in its successful form as it is currently experienced and utilised, will have a pivotal role in shaping future smart cities as the focal point for commercial activity, integrating social activity and sociality. This is not a novel positioning for the centrality of the high street. It is well documented that since the medieval period cities have been consistently arranged around a centre hosting commercial and social activities (Crawford 2005). Sack (1988) claims that the "actions of mass consumption are among the most powerful and pervasive place building processes in the modern world" (p. 643). As such, the successful high street is a visible, central element of a town or city's infrastructure and more subjectively is a key determinant in shaping its distinctive individual identity. In contrast, a failing high street cannot provide the starting point for evolution towards a coherent smart city. For individuals, as well as private and commercial parties, a failing high street risks becoming the impediment to the development of a genuinely integrated and functioning smart city. The broken high street already brings disunity to commercial and social life. If left unchecked, an unintegrated "smart" city, will be as challenging as the current situation manifesting itself among the many dysfunctions as a morass of cross-system incompatibilities. The implication of competing systems within the smart city are significant with the recognition of cities as "systems of systems" (Herandez-Munoz et al. 2011).

The aim of our paper is to recognise and document the operational management challenges that can be drawn out from community and everyday consumers expressions of the problems, both real and perceived, that confront the UK high street. Browne and Gomez (2011) have offer guidance in this respect with their identification of the supply chain challenges facing drinks delivery in an urban environment. Their (Browne and Gomez 2011) conclusions point to the need for public/private collaborations to resolve the very operational challenges they identify. We have also drawn upon the works of Peterson (2007), who uses future workshops as a method to initiate development for city logistics and Bugweg et al. (2011) whose study focuses on introducing new concepts and tools to enhance public/private collaborations. We take the direction of this exploration further by considering whether a breadth of stakeholder voices can have positive input in the planning of future smart cities infrastructure, and whether this plurality of voices can be refined and developed to present the imaginings for a unified functioning single smart city system of systems (Ackoff 1971). To deliver this aim we take a user-centric perspective by founding our work on data from a workshop that brought together a range of stakeholders including local community activists, independent retailers, property owners, town managers, consumers, academics and council officials. In order to contextualise our conclusions we first define the situation currently surrounding the UK high street - including recognition of the current absence of any smart cities in the UK and the acknowledgement that Bristol has recently laid out the ambition to create the UK's first smart city (Temperton 2015). We then identify the meaning and purpose of smart cities and define the key operations management challenges for the contemporary high street and city to positively move along this development trajectory. We report in detail on the membership, methodologies and outcomes of 
an "Imagining the High Street" workshop conducted in July 2014. The outcomes of this workshop are then analysed to identify the specific operational challenges that were brought out through the combined lived experiences of the workshop participants. The analysis from the workshop outcomes are discussed in relation to existing literature in order to build our contribution and offer some final conclusions.

\section{Background}

A significant amount of popular media attention in the UK has been directed to the apparent failure of the high street in the wake of the global financial instability and depression created by the banking crisis of 2009 (The Telegraph, 2011). The implication that may be inferred from this attention is that the decline of the high street is a new phenomena provoked by a massive and unexpected systemic failure in the banking sector. However, this decline is much longer term in nature and one that can arguably be traced back to post-World War II prosperity (Chaney 1985, p.23; Langman, 1991, p.117; Lorch \& Smith 1993, p.75; Lewis, 1990, p.121). Prosperity brought the realisation of the modernist agenda for massive consolidation in the name of convenience. $A$ philosophy that has subsequently proved to be dehumanising and soulless in experience (White and Hellerick, 1994). Commentators on the delivery and design of retailing in the US, Canada and Australia have been conscious of the decline of small scale shopping for a number of decades and have sought to explain the causes in a variety of ways (de Certeau, 1984; Baldassare 1992; Rigby, 2011; Blanco \& Fransoo, 2013). The UK situation has been experienced differently, in part, because the concept and practice of the high street persisted more determinedly against the advances of shopping malls and out-of-town centres into the 1980s, 1990s and 2000s. In many respects the framing question is not the popular media's position of "why has the UK high street failed?" but rather the more critically nuanced, "how did the UK high street manage to persist in its current form for so long?" (Chaney, 1985; Chaney, 1990).

Similarly, much of the rhetoric surrounding the claimed benefits of the UK high street is founded around nostalgic notions of pre-World War II - and even pre-20th century - consumption practices (Prus \& Dawson, 1991; Laermans, 1993; Pearson, 1993; Holt, 1995). This nostalgia identifies a range of features including the independence of retailers, the speciality of those retailers, the close proximity of these retail opportunities to consumers and the opportunities for customisation or personalised service (Wrigley and Lambiri, 2014). In effect, these points represent the complete antithesis of the modernist retail experience crafted by large national and multinational general purpose supermarket retailers. Policy makers have recognised the threats posed by the destablisation of the high street within local communities (Roberts, 2013). In 2006, the "All Party Parliamentary Small Shops Group" was established by the House of Commons. Their report "High Street Britain 2015" (2006) noted that homogenous high streets featuring big brand chain stores that push out independent retailers reduces sociability, erodes the "social glue that binds communities together", and ultimately "entrench social exclusion in the UK". 
The key operational issues and challenges that are now presented to town managers and retailers in the physical UK high street (described in the US and elsewhere as 'main street') and that are potential barriers to a future sustainable smart city are summarised by Sarmah (2014) in the US context in relation to governmental control.

Brick and mortar business owners watch with envy. "I believe that the mayor wants to make the city small business-friendly, but it isn't run very efficiently. There are a lot of bureaucratic processes," said Christie Hwang Jordan, who runs an acupuncture business in Chicago's River North neighborhood. Hwang Jordan has been trying for months to get the city to approve a banner for her storefront (After getting approval she will have to pay a $\$ 1,500$ fee to hang it.)

According to the U.S. Chamber of Commerce, Chicago has the highest fees for entrepreneurs among nine major American cities, including New York and San Francisco. The city also has the longest approval process for new businesses--an average of 32 days compared to five days in Boston. Illinois charges $\$ 500$ to register a basic limited liability company, while the fee is only $\$ 50$ in neighboring Michigan. The state fee is on top of local ones--which range from $\$ 250$ to more than $\$ 4,000$ depending on the type of business--most entrepreneurs have to pay if they set up shop in Chicago (Internet entrepreneurs typically only need to get a limited business license, which officials say can be applied for and issued within the same day).

Other challenges to the UK high street manifest themselves in the form of low level of available car parking space, expensive parking fees, expensive public transport (Beirao and Caral, 2007), the snowball effect of high retail vacancy rates (Jones, 2010), low levels of supportive business clustering, consolidated property ownership (Jackson and Watkins, 2011) and ineffective town planning (Brown and Gomez, 2011; Collis et al. 2000).

\subsection{Shopping, the High Street and Smart Cities}

A great deal of attention is being paid towards the future of the places we live in from a number of different sectors including policy makers and academics (Wrigley and Lambitowri, 2014). The Copenhagen CleanTech Cluster (2012) have taken up an approach similar to the one presented here to introduce grassroots stakeholder input into the debate. Multinational corporations such as IBM, Samsung and Intel (Global Connections, 2013) have recognised the significance of place and the impact that changes in the urban environment will have upon their own businesses - both positively and negatively. A key term that consistently arises throughout discussions surrounding the future of urban environments have been grouped around the moniker of 'smart cities'. This has "become part of the language of urbanization policy, referring to the clever use of IT to improve the productivity of a city's essential infrastructure" (Hodgkinson, 2011, p.2).

As previously mentioned and in the absence of academic or practical consensus regarding the meaning of smart cities we take as a starting the recognition by Herandez-Munoz et al. (2011) of cities as "systems of systems." By contrasting existing smart cities literature with the high 
street literature we can see that a number of key questions remain unexplored in the planning and growth associated with smart city development. For example, can a "smart" city with unintegrated commercial and public systems be planned and built by external commercial stakeholders, policy makers and academics alone? What are the key contributions that community members or geographically proximal inhabitants make to the planning of a smart city? How do top down planning approaches manifest themselves as cross-system city-wide developments? Further questions concerning the impact of a changing high street on the smart city also exist. For example, if the high street is both a visible and central element to a city's infrastructure what impact does a declining high street have in making it smart? Previous literature recognises the risk of a failing high street becoming the starting point for a smart city (Sack, 1988). Examining the impact and perceptions of a wide range of city "users" appears to be an imperative component of designing the new user experience of future smart cities.

With cross-system integration and compatibility becoming a ubiquitous consideration in the development of new technologies for all aspects of everyday life (Rigby, 2011), attention is now turning away from issues of personal IT access and baseline skills to discussions about where technologies fit into the urban landscape for the overall benefit of consumers, businesses and governments (Nam and Pardo, 2011). However, Graham (2014) highlights how very little is being done to engage the people who inhabit these urban spaces. He argues that the importance of debate is to garner opinions so that smart cities are designed to meet community needs. The relative absence of this form of debate reinforces the longstanding claims of previous literature that too much control over how smart cities will be and are currently being developed is locked within the control of multinational corporations (Vaughan, 1978; Townsend, 2013). While this situation continues the designs of future landscapes will inevitably be set out to achieve the commercial interests of the largest multinational in pursuit of value creation defined in the narrowest form as the financial bottom line (Korten, 1996).

This paper critiques key corporate and government decision makers in the context of smart city planning by actively engaging with the people who will be the main inhabitants and consumers of smart cities. Closed systems of urban development brings the prospect for the creation of levels of distrust amongst citizens discouraging them from engaging in or becoming users of smart cities. In contrast, presenting small but succinct insights into the opinions of citizenry allows policy makers and commercial interests to obtain better understanding of local needs and aspirations amongst individual and communities that can then become acknowledged - if not embedded - into future smart city designs.

\subsection{The UK High Street}

The rapidly evolving retail landscape in contemporary Britain is often a reflection of the local situation (Dimitriadas and Koh 2005). The high street has many guises that is dependent upon its physical and economic location. For example, the notion of a village high street with essential services being accommodated or a 'trendy' high street populated with small independent boutique shops is a distant image from a high street located in an area of high social deprivation that hosts charity shops, bookmakers, fast food shops and potentially a token 'corner shop'. 
These individual retail locations require nuanced understanding to be meaningfully injected into generalised high street discussions. This need to understand the context of a high street has become even more important in light of recent reports that independent retailers are plugging high street gaps left by the exodus of chains stores (Wood, 2014). The British Council of Shopping Centres (2013) state that high street vacancy rates were at $14 \%$ and that there are 287,000 shops currently trading in the UK but the report provides little context for these statistics. In contrast, Philip Cox, Director of Land and Development in the Department for Communities and Local Government (2014) stated that town centre vacancy rates were $11 \%$ in January 2014 which represented a slight decrease from previous months. However, the footfall on the high street was recorded as being down by $10 \%$ over the last three years (excluding London). Irrespective of the comparative veracity of these figures they provide some indication of the growth, albeit a minor improvement in the vacancy rate, and overall increase in retail sales compared to the previous year.

In 2012, up to 400 town teams across the UK which had missed out on the 27 funded Portas Pilot schemes (Department for Communities and Local Government, 2012) had the opportunity to become Town Team Partners (in what was labelled the Town First Framework) giving them access to part of a £5.5m support package and other initiatives including web resources hosted by the Association of Town and City Management (ACTM)'s '100 Ways to Help the High Street'. There was a further $£ 1 \mathrm{~m}$ Future High Street funding available for businesses to encourage shoppers back to the high street. By 2013 the UK Government had embedded, as part of a long-term economic strategy, a further $£ 1 b n$ support package to save the high street and ultimately encourage regional job growth. New initiatives for consumers, include the relaxation of parking policies, reviews of double yellow lines (no parking) laws and reduced car-parking penalties were introduced with the intention of facilitating local shopping rather than visits to outof-town retail parks. For business owners there was a reduction in businesses rates, a capping of retail price index and $£ 4.7 \mathrm{~m}$ being allocated for digital high street innovations. These actions can be viewed as demonstrative proof of the government's acknowledgement of the multidimensional demise of the high street and the need to encourage economic growth within this sector. A "Future High Street" forum briefed to facilitate the implementation of these initiatives is made up of a variety of members of government, public bodies, Mary Portas and retail business owners as well as representatives from Tesco, McDonalds, and Costa Coffee (Portas, 2014). The forum members are all visible on the high street. In contrast there is a lack of citizenconsumer representation amongst the forum membership. Not unexpectedly, within a year of their initiation the Portas Pilot and the town teams partners scheme exposed a variety of challenges (Department for Communities and Local Government, 2013). There have been reports that in ten out of the initial twelve Portas Pilot schemes the number of empty shops in these locations had increased and a Freedom of Information (FOI) request (e.g. https://www.whatdotheyknow.com/request/mary portas pilot scheme,

https://www.whatdotheyknow.com/request/portas pilot) evidences that a relatively small amount of money awarded to the pilot towns has actually been spent. Popular media commentators argue that this is a result of the layers of bureaucracy subsequently introduced by the town teams to manage the process (Valentine, 2013). Compounding these accusations has been a damning admission by Portas - who herself lost confidence in the scheme - with the 
announcement that "she had severed all lines of communication with the government" (Haslett, 2013) as she believed it was not a number one priority [of the Government] and possibly a PR stunt. Additional concerns regarding the efficacy of the policy and planning procedures regarding the Town First Framework were raised by The Association of Convenience Stores (ACS 2013) who commissioned an investigation into how local governments were applying the impact tests of the National Planning Policy Framework (NPPF), a random fifty applications were reviewed and $70 \%$ of the applications were approved for the development of out-of-town retail space. There is a strong disconnect in the rhetoric found in a number of associated policy documents including the Planning Policy Statement 4: Planning for Sustainable Economic Growth (PPS4, 2009). Town centre planning strategy guidance stresses the importance of defining a "hierarchy of town centres in an area" (Department for Communities and Local Government, 2014). Surprisingly, the PPS4, a planning policy that sets out the government's national policy for economic development and planning for centres, sustainable growth, consumer choice and promoting competition in town centres there is no reference or mechanism for consumer consultation. Whilst the rhetoric of the policy places importance on all town centres as the "glue" of the community, the guidance encourages prioritisation based economic growth and vitality; suggesting in the narrative that town centres in wealthier boroughs will receive more support.

Following the Portas review there has been a move from Community Led Planning (CLP) to Neighbourhood Planning. This move is a renewed attempt at engaging members of the community in actively developing local planning policy rather than remaining the passive recipients of planning decisions and their subsequent outcomes.

\section{Methodology}

\subsection{Creative prototyping}

The methodological inspiration for this work came from the Copenhagen CleanTech Cluster (2012), a group who focuses on the research and implementation of clean energy sources. The method they have devised incorporates consumer stakeholders into the debate and discussion regarding future cities. However, the perspective employed by Copenhagen CleanTech Cluster (2012) represents a significant conceptual and operational distinction to the current paper as Scandinavia already has already well-developed projects to develop smart cities. Our work is clearly founded upon different commercial and social situations. In Denmark greater degrees of governmental influence and support have supported development towards single coherent smart city systems.

Instead of basing new development on narrow political decisions, we try to adopt a much more open and democratic approach to the big questions surrounding the development of the city. In the Smart Aarhus initiative this is done by creating a number of different working groups, which consist of citizens, researchers and businesses, who together try to address some of the common challenges we face. Example workshops include 'smart supply', 'open data', 'digital entrepreneurship', 'sustainable development', and 'public-private partnerships'. 
Although our conceptual inspiration is shared with the Copenhagen CleanTech Cluster's work we have also employed two innovative approaches that elicit greater depth and enabled higher levels of creativity to be brought out from participants. In this respect the work of van Laere et al. (2006) with the Amsterdam Police Force to coordinate and plan future activities is a useful precursor to our own work. The work with the Police Force asked participants to apply a taskactor model and identify individuals, tasks and information flows in their working day (va Laere et al. 2006, p.562). Unlike the va Laere et al. (2006) study of police force members only, we move away from studying a heterogenous group of participants, to observing a mixed group with varying agendas relating to high street shopping, including retail owners, consumer/ customers, City Council employees etc. We also focus on the use of shared narratives to bridge the gaps that can occur in individual knowledges and experiences relating to a topic. Enabling collaboration between the participants allowed them to work together to build their final ideas and imaginings.

Data for this study was collected through a collaborative workshop entitled 'Creative Prototyping the Future High Street'. Petersen (2007) adopted the future workshop approach in order to develop concepts of city logistics with stakeholders. They argued that this process allowed all participants "with new knowledge to be applied in their daily fields of work" (p.616). In a similar vein van Laere et al. (2006, p.561) claim that organisational situations can be conceptualised by describing the attributes and actions of perceived objects." The aim of our workshop drew inspiration from Petersen (2007) and applied innovative and creative methods to bring together and promote discussion amongst a variety of stakeholders about the shape and form of the future high street. Creative methods act as a means to bridge the complexity of discussing an observable situation for a diverse range of stakeholders who are all operating with a series of preconceptions that shape their existing understanding. This situation itself reflects the types of information asymmetry that can be identified in supply chains between suppliers and buyers (McCarthy et al. 2103) in the high street and elsewhere as well as the variability of understanding and knowledge that exists between government agencies, commercial organisations and individuals.

The workshop was aimed at a range of participants from professional and social backgrounds including members of community groups, academics, retailers, digital evangelists, high street shoppers and members of the local council. The invitation for the workshop targeted specific individuals drawn from the personal and professional contacts of the research team in Inner City Manchester. Invitations were sent to local councillors, community groups and retail organisations from two specific geographical locations Inner City Salford and South Manchester. To ensure that operation of workshop remained manageable and to provide a fair representation across stakeholders, the the total workshop attendance list was limited to 25 and we aimed to have a range of members including a minimum of 5 community groups, 5 academics, 5 retailer's, 5 digital evangelists, 5 high street shoppers and 5 members of the local council. In order to ensure this cross representation as acceptances were received we tailored invites to those areas that could be underrepresented (such as). The final attendance list 
detailing the background descriptions of participants is provided in Appendix 1. In summary the makeup of participants who attended were as follows:

4 academics (specialists in related fields), 3 community organisation representatives, 4 consumers/customers, 3 government policy makers, 3 retailers, 1 digital evangelist /technology expert. Having a cross section of participants ensured a variety of opinions and perspectives as well an amalgamation of experiences in relation to the existing high street. The workshop took place in July 2014 at MediaCityUK, Salford based in the Northwest of England and a total of fourteen external participants contributed to the discussions. This location was selected due to its good links to public transport for the local community as well as being a popular hub of digital creativity, learning and leisure. An independent facilitator as well as members of the research team led the workshop. Other members of the research team participated amongst the workshop in order to actively engage with participants, contribute towards the activities and to gain an in-depth understanding of the participant's experiences.

Science Fiction Prototyping (SFP) is one of the many available approaches to bring encourage creativity in workshop participants. The concept was originally developed by IBM futurist Brian David Johnson as a mechanism to assist engineers to think about the consequences of their design decisions in a human and accessible way (Kohno and Johnson, 2011). However, the approach has been adapted for a variety of uses beyond engineering design including teaching and learning and workshop delivery (Shumei and Victor, 2014; Wu, 2013). The advantage of science fiction prototyping is that it is based on a generally familiar narrative genre that does not limit description or creativity but rather acts as an easily accessible, familiar and workable framework. As it is based on a narrative structure science fiction prototyping also incorporates an automatic logic that requires connections between the beginning, middle and end of a story as well as sufficient elaboration of characters, events and actions that enable any third party reader to understand the purpose, focus and direction of the story. SFP also removes the boundaries of existing social mores and organisational conventions that limit the imagination - in other words in the realm of science fiction prototyping anything is possible. Our own knowledges and preferences are what constrain the any SFP that is developed and working in pairs or groups provides sufficient grounding in a common shared sociality to ensure the story is 'just' possible (Bell et al. 2013). With this set of starting points, participants commence with the most minimum set of guiding principles and few pre-existing givens set by the activity.

The concept of 'Science Fiction Prototyping' was introduced to the participants and they were then encouraged to apply this method by creating characters, events and stories surrounding their vision of the future high street. Participants worked in small teams in order to support each other and to further extend and co-develop their ideas into a story. Each group was asked to write a short story or narrative that captured their vision of the future high st. Stories were written in traditional style with pen and paper. They were subsequently read out by the participants to the whole group. Collaborative working offered the potential to uncover new insights when experience and knowledge is accessed, shared and developed. It also allowed participants to feel more confident to act upon shared knowledge and further embed these insights into their stories. Working as a group also "offer[s] the possibility that the insights and knowledge of each member eventually becomes the insight and knowledge of the whole team" 
(Rasmussen, 2006, p. 56). Ideas were then shared amongst the whole group and potential outcomes of these factors were also discussed, consolidating and actualising these ideas into longer and more complete narratives. Stories and ideas were captured, by an independent facilitator throughout the workshop, as summary transcripts from each participant's recitation of their story, reinforcing the plurality of their voices.

The ideas and the narratives that were created by participants through Science Fiction Prototyping were then developed further using Lego Serious Play. Frick et al. (2013) define Lego Serious Play as "a facilitated workshop where participants respond to tasks by building symbolic and metaphorical models with Lego bricks and present them to the other participants" (p.3). This particular method was employed for a variety of reasons. According to Rasmussen (2006) Lego Serious Play facilitates collaborative and positive interactions amongst groups of different backgrounds and mixed abilities, providing the means to tailor real time strategies when working amongst decision making situations. Using Lego allowed participants to actually realise their vision of a future high street by interactively building models because "when people construct things out in the world, they simultaneously construct theories and knowledge in their minds" (Rasmussen Consulting, 2012, p. 5). This task enabled participants to understand some of the physical, visual and practical applications of their understandings and proposed ideas. Another advantage of this method is that Lego is a highly familiar tool for creation that offers almost limitless possibilities but yet still provides boundaries that can be easily managed so users do not become overwhelmed. The general familiarity of participants with Lego reduced the need for induction to the activity. Bringing together a group of people from a range of disciplines and backgrounds can bring barriers to interactive communication and shared vocabularies. Science Fiction Prototyping reduces this complexity by forcing participants to speak through a single shared genre in which no-one is a "native" speaker. Lego Serious Play as a method also eases these basic communication issues by providing a creative yet accessible means for participants to express their views and tell their stories, regardless of social or professional background (Gauntlett and Holzwarth, 2006; Gauntlett, 2007). 


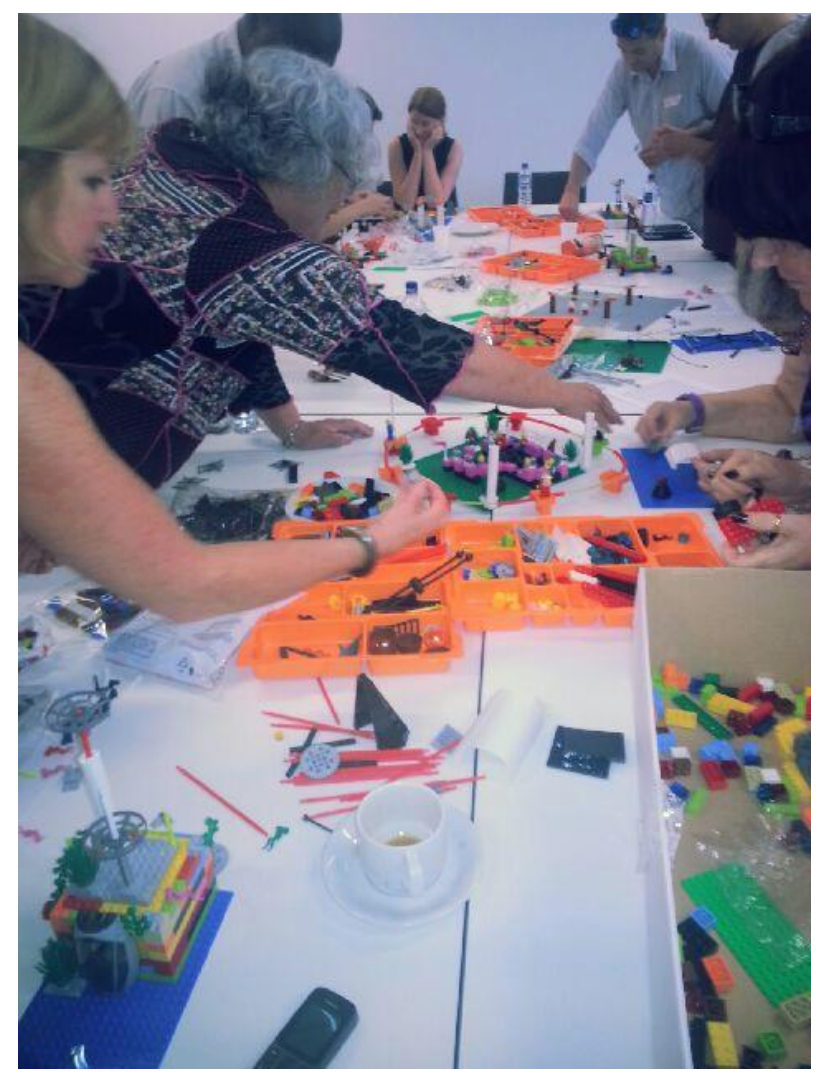

Figure 1. Individual and collective Lego Serious Play

The researchers led a discussion with the participants about the ideas and rationale behind their creations throughout the building process. In many cases this also resulted in participants refining their Lego model and in some instances joining projects together as a symbolic recognition of common understandings and like-mindedness. When finished the participants, a cohesive group, then explained the rationale behind each of their models. This data was captured on video and through photographs and provided another layer of understanding to some of the qualities and artefacts that participants wanted and expected in a future 'smart' high street. This process also allowed for participants to mutually understand and recognise some of the current and prospective future operational issues that the high street is facing.

Data from these activities was captured through qualitative methods and the application of an interpretivist approach (Walsham, 1995). The method of content analysis has been applied in order to draw out meaning from the data. This has been achieved through a systematic manual process of coding and identifying themes and patterns (Babbie, 2010) and eyeballing (Willis, 2007, p.298) each story individually. It is the activities of the workshop and the participants stories themselves that was analysed. As previously mentioned all conversations and interactions throughout the day were recorded and further to this the individual and group narratives were written down and gathered up (with the consent of the participants) at the end of the day. The stories themselves were analysed according to Rasmussen Consulting's (2012) method, that is to source the overarching themes from the narratives, look in detail at the description the narrative has provided, and from this identify the technologies associated with 
these descriptions. This first sweep of analysis (see table 1.) was then nuanced with a second iteration of analysis to the specific themes associated with production planning and control of a smart city. The dominant themes and theoretical factors found within the literature were identified as the built environment, transport, spaces empty (in this case), planning and control. These specific themes were then again applied to inform the second analysis process (see table 2.). In finalising the analysis it became clear that three dominant themes had emerged; the application of ubiquitous but invisible technology to the high street, the methods for deploying a consultation process in the planning of a high street and identification of the mechanisms for enabling a greater breadth of stakeholder voices.

\section{Analysis}

The data collected within this workshop was analysed with particular reference to stakeholder aspirations and individual fears associated with an imagined future high street. The ways in which stakeholders saw technology integrating into future smart cities was also captured. The volume and richness of the inputs highlighted how this form of research data can be used to inform town planners in planning a future high street. An effective consultation process is defined as "a two way process of openly sharing and exchanging information, understanding different views, listening and responding to suggestions" (Planning Aid England, 2012). A number of parallels exist between the workshop in this work and that of Bititci et al. (2007) in their efforts to understand synergy in collaborative enterprises. The three general aims of Bititci et al's (2007) workshop; a) to understand the situation, b) to make a self-assessment of the situation and c) to assess the maturity of progress towards an outcome or resolution captures the three generalised steps of the workshop process. The final action of maturity assessment can itself be examined in more detail on a case by case basis (Bititci et al. 2007) but is often an underplayed aspect of workshop activities. The willingness of the participants to exchange, listen and respond during the workshop reflected a confidence that they were being listened to, their inputs were being captured and that the innovative methods of science fiction prototyping and Lego Serious Play were providing them with new knowledge, skills and techniques that could be 'taken away' and applied in their own realms of activity and experience.

Table 1 offers a condensed overview of the various storylines and imaginings of the workshop participants. A range of ages and interests are represented in the stories. Both male and female characteristics were presented although there is a disproportionate absence of children, youth and those under eighteen in the stories. In reflecting upon this observation, further work is required to incorporate the voices of younger members of the community (those under eighteen) in a meaningful and productive way. The researchers plan to undertake further work aimed at addressing and understanding these stakeholders through more practical workshops about the future smart city.

\begin{tabular}{|l|l|l|}
\hline $\begin{array}{l}\text { Overarching } \\
\text { Theme }\end{array}$ & Illustrative Data & Technologies \\
\hline Identity & Smartcard: stores personal details for & $\bullet$ Smartcard \\
\hline
\end{tabular}




\begin{tabular}{|l|l|l|}
\hline & $\begin{array}{l}\text { payment, delivery, consumer profiles, } \\
\text { downloads personalised offers before } \\
\text { leaving home, home delivery arranged with } \\
\text { one swipe. } \\
\text { Range of characters in stories (ages 18 - 70; } \\
\text { majority women; some have disabilities) the } \\
\text { imagined high street that is described meets } \\
\text { the needs of each. }\end{array}$ & Mobile devices \\
\hline Experience & $\begin{array}{l}\text { Plan the day in advance } \\
\text { Interactive wall alerts shopper to information } \\
\text { about events, locations, activities, updated in } \\
\text { real time on the street } \\
\text { Smartcard: connects to interactive wall, } \\
\text { receives and sends person to person } \\
\text { connections “your friend X is nearby" } \\
\text { People and family oriented space, music and } \\
\text { entertainment opportunities, creative spaces }\end{array}$ & $\bullet$ Interactive wall \\
\hline Smartcard
\end{tabular}

Table 1. Emergent themes and illustrative data from the stories written at the SFP workshop.

Although the full details of the stories developed by the workshop participants cannot be presented in their entirety Table 2 summarises the core activities and operational challenges raised within the narratives of future high street activities. The consistent theme across the stories is the essential inclusion of socialisation practices and entertainment. The workshop participants' imaginings confirm the importance of 'people' within the cityscape - as a space of social gathering, dining, entertainment and calm were all expressed as desirable qualities of the future high street experience.

\begin{tabular}{|l|l|l|l|l|}
\hline $\begin{array}{l}\text { Built } \\
\text { Environment }\end{array}$ & Transport & Empty Space & Planning & Control \\
\hline $\begin{array}{l}\text { Start up businesses } \\
\text { present in the high } \\
\text { street }\end{array}$ & $\begin{array}{l}\text { 21st century mini } \\
\text { children's railway } \\
\text { A horizontal } \\
\text { paternoster } \\
\text { Transport from }\end{array}$ & $\begin{array}{l}\text { Movie on glasses, } \\
\text { in-show } \\
\text { advertisement } \\
\text { Post-Tesco } \\
\text { apocalypse }\end{array}$ & $\begin{array}{l}\text { Automated transport } \\
\text { system in high street } \\
\text { is always on/always } \\
\text { available } \\
\text { 21st century mini }\end{array}$ & $\begin{array}{l}\text { Environmentally } \\
\text { protected-covered, } \\
\text { always bright, green, } \\
\text { Clean air/low noise } \\
\text { delivery }\end{array}$ \\
\hline
\end{tabular}




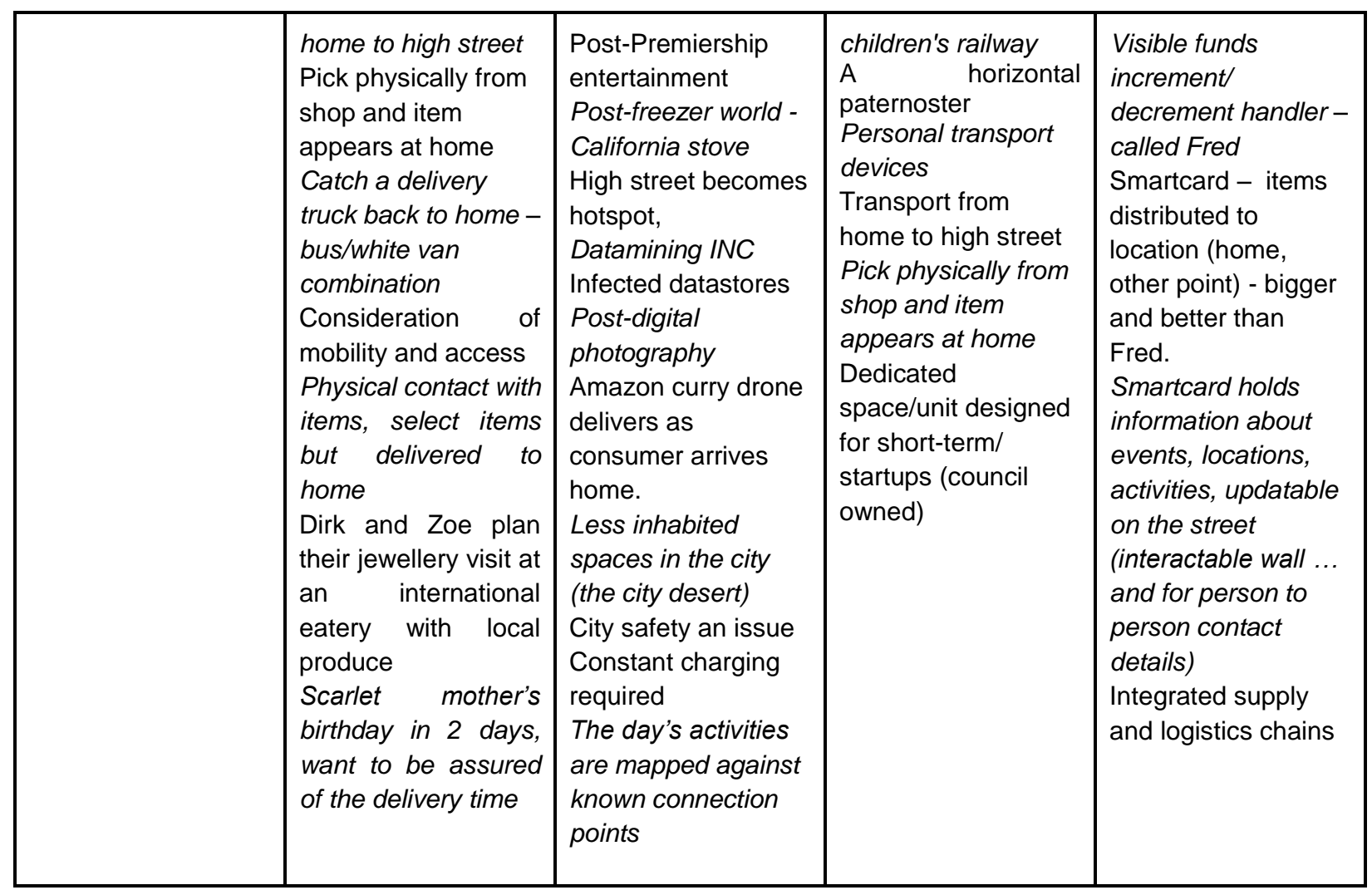

Table 2: Present and future activities and operational management challenges in the future UK high street

The narratives provided by workshop participants tended to readily fall into three themes; a) the importance of ever present but invisible technology, b) the forefronting of people in the smart city and c) the need for wide-ranging stakeholder input and participation in planning. The individual narratives and themes offer insight into the imagined future smart high street and the potential to create it as a functional and integrated system of systems (Ackoff 1971). Workshop participants did not necessarily agree about the specific details of any of these three overarching themes and in some cases presented completely antithetical visions. However, in doing this the topic is highlighted as a challenge for the planner and an operational issue requiring contextual understanding that brings at least some satisfaction for each of the different stakeholders.

\subsection{The importance of ever present but invisible technology}

The application of technology played an important role in many of the participant's narratives of how the high street may evolve and develop. The visions of technology ranged from LEDs being embedded within clothing to computer controlled vehicles.

The relationship between the digital and the physical was also part of this theme that was frequently referred to throughout the workshop. Some participants spoke about the desire to have a link between shops past and future by the merging of physical space in order to create interactive, digital displays. Some participants compared this relationship with the website 
Etsy.com, which utilises online space to host a digital craft fair. Participants spoke about choosing items in shops and then these purchased goods arriving directly back at their home, allowing them to still experience shopping but without the current inconveniences that come with it. This demonstrates how participants appreciate the opportunities that may be provided by the application of digital technology and an integrated supply chain and delivery system in this particular example, but also the continued desire for experiences that more tangible aspects of the physical high street experience.

Participants also mentioned other examples of technology that would enhance the experience of the high street by bringing heightened levels of convenience without directly damaging the social and positive experiential aspects of shopping. This included the use of smart cards to hold information regarding events, locations and activities including the possibility to update this information - 'on the go' - on the street. The broad consensus of the workshop was that this imagined smart card would present a single 'easy' alternative to mobile phones. The smart card would avoid the need for a confusing and even conflicting collections of apps and instead got directly to the individually essential and necessary information in an accessible way. The workshop participants went further by imagining an interactive wall in which the smart cards could connect and present a personalised experience customised to each individual. Other participants found existing smart phones to be an accessible means to connect to the locality and retrieve information but voiced a desire to have a more convenient link to the environment through personal connection points as well as places to charge and update personal devices. The constant need for power as individuals moved through the high street was also a minor but persistent concern for many workshop participants.

Some participants also acknowledged that they found the overt presence of technology to be a hindrance in their everyday lives, claiming that it sometimes takes over and can be difficult to disconnect and manage their off-line time. The participants who expressed this experience advocated a high street with allocated 'technology free zones' that create - through technology an area where the use data access is not possible and provides respite from an increasingly digitised existence. While a technology-free zone was appealing to some participants in the workshop broader consensus was reached that argued for ever present "invisible technology". This mediated position that came out of the workshop revealed a desire for access to technology but did not want it to determine, or predominate visually, within the high street. The position was clearly a 'best of both worlds' stance that would shape the physical form of the future smart city.

\subsection{The forefronting of people in the smart city}

The theme of planning priorities and people was also a focus within discussions across the groups. Older participants and those who have cared for older relatives expressed the need for a safe space when navigating the high street including the removal or mitigation of hazards such as tramlines and poor street maintenance. These dangers can be reduced with the application of smart planning techniques for walking routes that accounts for accessibility and mobility as well as distance. Some participants even suggested physically leveling the entire high street in order to allow it be more accessible for all. This is the line of argument that has 
already been taken up by some cities through the implementation of shared space streets (Department for Transport, 2011). Personal transport solutions were considered as one potentially strong solution to current issues of mobility, access and the reduction of motor vehicle traffic.

The productivity of the high street space itself became a focus further discussion and of concern. Many of the participants expressed a desire for a more authentic shopping experience with shops and activities that could not be found elsewhere as an enticement for themselves and others. Some suggested that this initiative should being supported by local councils through their commitment to reduced rates and facilitating pop up shops as well as providing greater flexibility for, and access to, smaller more unique businesses. This could potentially open up new opportunities for enterprises, high street shoppers and ultimately the economy. The town square was highlighted as a location to blend multiple experiences including an area to be able to meet others, socialise, and be entertained. Participants highlighted how cultural spaces often found with the high street such as libraries, museums and churches could fulfill the role of multifunctional coffee shops and social spaces by blending current services and cultural experiences in order to attract more visitors.

Participants went even further to express a need for greater control over the high street environment itself in relation to protection from the weather. Initially the comments centred around the perceptions of persistently poor British weather and how the regularly of precipitation mitigates against outdoor visits to the high street. These sentiments raised the concern that the imagined high street could be too readily transformed into a copycat of existing indoor shopping centres and all of their claimed benefits and advantages over the high street (Goss, 1993).

\subsection{The need for wide-ranging stakeholder input and participation in planning}

All the workshop, participants recognised the need to represent different people and interests in the design of the future smart high street. It was also acknowledged that despite the diverse range of people that attended the workshop there was a notable absence of young people and teenagers present at the workshop. Many participants expressed their disappointment that this particular demographic was not represented at the workshop and tried their best to accommodate this by incorporating ideas that they believed would appeal to younger audiences including unique shops, green spaces and safe places for people to meet and intersect with friends. All of the participants however recognised that this was a poor substitute for actual participation from this stakeholder group.

All of the participants expressed a desire to keep the high street as a local experience and expressed alarm at any form of intensified corporate vision for the high street. The impact of these visions are already well-evidenced throughout the UK where many of the high street chain stores provide the same products and experience irrespective of local context or specific community interests or needs. The homogenisation of the high street is a well recognised phenomena. Many of the participants collectively longed for "authentic" experiences that they felt were was once available. This line of discussion became the expression of a desire for the 
high street to be unique to its location and not dictated by the economies of the mass consumption of good or services. Some discussed the experiential excitement of discovering a place of interest by chance and spoke of the high street as a form of nostalgic theme park where all their needs and curiosities could be simultaneously met. This largely imagined view of the "old" high street could be operationalised through the construction of smart high streets as outlets for luxury goods with this physical presence acting as a hallmark for high quality and exclusivity.

As out-of-town shopping centres and online shopping have become accessible, consumers have no longer required a heterogeneous high street. Consumers can buy standard products more conveniently elsewhere; in out-of-town retail parks, large supermarkets and through online home delivery. Shoppers who look to the high street are more likely to be seeking wider choice and individual options. However, the independent retailers that bring diversity can rarely afford high street rents. A further conundrum is that in order to pull people back to the high street requires a critical mass of this diversity of goods and shops. It is significant to note that charity shops and similar (vintage, upcyclers etc) have generally resisted the flight from the high street. Most of the more desolate UK high streets are host to at least one charity or used goods shops. This can be attributed to a number of factors; the low rents offered to charities by councils, the economic downturn affecting spending power, the revival of consumer "make do and mend" attitudes, and the trend towards "individual" or "retro" style. What is key is that these traders offer products that are available transiently and serendipitously and not readily represented through online ecommerce. At the specific time of discovery, in that specific place, each item that is found is a "one off". The shopping experience of the past is to some extent captured through the local residents bringing stock (the things they no longer need) to sell on to other local residents. These actions present an emergent opportunity to promote social engagement and community reinforcing the importance of human interaction for exchanging information (Dimitriadis \& Koh 2005, 551). Whilst it is no longer viable to try to recreate an imagined or real high street of the past with the input of specialised craftspeople, elements such as the social experience and the individuality of the products available remain particularly relevant (Holmes et al. 2012). Recognition of the importance of the social supply chain offers ways of incorporating these people-based elements of experience into new ways of shopping (Fletcher et al. 2013). This study explores these issues and proposes new ways of inclusive planning and design. We recognise the limitations of the study and look to address these through further research. Firstly, only one workshop was held. Richer data could be gathered from a series of workshops

allowing from pooling of data and cross case comparison. Next, younger members of the community were not represented in the workshops. We intend to conduct further research targeting those under eighteen. Further, the group of participants we drew together were from different localities. Although meeting at Media City was considered a strength given the focus on creativity that pervades, this made the research rather abstract. Future workshops will be carried out within communities with a focus on the future development of a specific high street.

\section{Operational management challenges and the smart city of the future}


Recent policy development and political rhetoric regarding the UK high street suggests it will be pivotal in shaping the future of smart cities as a focal point for commercial activity and ultimately sociality. Shapiro (2006) has argued that it is extremely important to consider the integrative abilities of digital technologies throughout urban environments and how application of these technologies can improve the overall general quality of life including how people work, travel, play and live. While the relationship between technology and the smart city agenda is undeniable in this paper we extend Shapiro's proposition and explore the issue of smart city development through the lense of 'engagement work'. We have examined input drawn from a range of community and individual stakeholders who would not generally have a voice in conventional town planning processes. The workshop participants present a future imagining and perception of a changing city that is technology enabled but people orientated. We have argued that the active involvement of these individuals in the research process can enable a deeper understanding of how technology and people can be brought together productively to create smart cities that are socially inclusive while remaining relevant in a commercial and retail sense. We contend that the visibility and centrality of the high street makes it an integral element to a locality's infrastructure and consequently a key determinant in shaping the distinctive identity of a future smart city. Local authorities, town centre management and other agencies are increasingly playing a key role in shaping town centres and high streets but we have found little empirical evidence for the basis and source of these decisions or how residents' voices have been incorporated in the process.

This paper makes a further contribution through its methodological techniques and the capacity of these techniques to bring out the voices of underrepresented stakeholders. The narratives that were created by participants through Science Fiction Prototyping and then visualised using Lego Serious Play illustrate that for local interest groups the high street is indeed the glue that binds a community together - at least it still remains this way in the imaginations of our workshop participants if no longer still evidenced in reality. The advantage of Science Fiction Prototyping (SFP) was confirmed in the study when participants produced their own narratives. The combination of the SFP techniques coupled with Lego Serious Play work constructively together. The combination of methods enhances description and brings out a group's creativity to create a seamless - and enjoyable - experience that is also a mechanism for readily creating a coherent contribution to social debate (Rasmussen, 2006), as well as providing a familiar and workable framework for the organisers (Shumei and Victor, 2014; Wu, 2013, Bell et. al. 2013). The only limitations encountered from the use of these methods were in the initial stages of the workshop, where some participants expressed reluctance towards play as a technique for serious work, an issue that is apparently common amongst workshops of this format (Roos et al. 2004). However, after a full explanation from workshop facilitators and discussion amongst the group, these particular participants became visibly more vocally and enthusiastic towards the methods being utilised. The method of Science Fiction Prototyping and use of Lego Serious Play enabled the participants to break down conceptual boundaries, articulate ideas, overcome preconceptions and access their own creative imaginations around the topic of the future high street. As each group produced different ideas, and as it was not the aim of the workshop, a single definitive imagining of a future smart high street was not created. However, the process illustrated the value of using innovative methods to capture a greater breadth of stakeholder 
voices in town planning and potentially in other forms of social engagements requiring broad stakeholder input.

Based on the data gathered from the workshop, the high street in a future UK smart city will have three clearly identifiable qualities that will at least partially satisfy and engage the broadest possible range of stakeholders. There is a desire to continue building and enhancing the opportunities that technological developments bring to the high street; that technology should not predominate but rather be ever present and covert within the high street experience; and that the operationalisation of high street planning and development must forefront people and their interactions with each other. The first quality identified is that the high street will be technology-rich. Responses from our research participants showed enthusiasm for using technology to solve problems and therefore confirming Rigby's (2011) proposition that the constant development of new technologies is increasingly ubiquitous throughout every aspect of everyday life. However, attention is now turning away from issues of basic IT skills provision to discussions about the fit of technology in the urban landscape and how it can be utilised to the overall benefit of consumers, businesses and governments (Nam and Pardo, 2011). The desire for quality IT infrastructure on the physical high street should not be viewed as a reflex response by retailers to compete on the basis of price or 24/7 availability with online retailers but instead as an underlying enabler that enhances the experience of shoppers in the physical street. These enhancements may come, for example, in the form of linking friends, finding new retailers based on previously expressed interests or direction to seasonal or pop-up events. Information technology will not predominate the space but become omnipresent and covert. This leads to the second quality of the future high street in its forefronting of people and their interactions with one another. an important quality in light of Shapiro (2006) assertions and the importance of the integrative abilities of digital technologies throughout urban environments including how the application of these technologies can improve the overall general quality of life. This may necessitate the slow reinvention of the role of the retailer to incorporate aspects of tutor, critical friend, tourist guide and fellow co-consumer. Similarly some retailers will discover the context of the night-time economy to satisfy consumers. For example fashion stores would open from 8pm until midnight to cater for nightclubbers with a free delivery home of their old clothes or a shoe store might open at 2am to swap high heels that have already served their purpose for more comfortable flats. A smart people-centric high street is not defined by the physical buildings or the constraints of regimented opening hours but by the context of the events and activities that occurring within the space. As Wood (2014) has illustrated individual retail locations require more nuanced understandings to be injected into the generic concept of "high street". To realise the smart future high street planning and development will be based on empirical research that engages the plurality of voices who express a vested interest. The breadth of voices presented in the workshop illustrates the value of this polyphonic approach to planning. Graham (2014) highlights concern about how very little is being done in town planning actions with the consideration of engaging the people who inhabit communities. The workshop conducted for the research presented here provides a clear indication of how the imaginings of communities members can contribute to the design of smart cities. A form of control that Vaughan (1978) and Townsend (2013) argue is largely locked within the command of multinational corporations. This alternative vision can design strategic and sustainable future landscapes that will break away 
from short-term commercial interests that are based around realising profit within a shorter accounting period (Korten, 1996).

From this research it is evident that citizens look to the high street as a generally social space rather than simply a transactional place. Stories from all of our workshop participants foregrounded the importance of socialisation rather than shopping in the high street (Chaney, 1990; Lewis, 1990). Similarly nostalgia could be clearly identified as a strong force in the stakeholder imagining of an range of high street features including the need for independent retailers, the specialism of those retailers, the close proximity of these retail opportunities to the consumers themselves and the opportunities for customisation or personalised service (Wrigley and Lambiri, 2014).

While acknowledging this stakeholder viewpoint it is also clear that the full range of interests of stakeholders in the future high street will never form a complete consensus. It is commercially unsustainable to continue to offer broad-based and generic retail experiences without consumer input and expect a continuation of the success of 1970s and 1980s high and mass consumerism. Future smart cities must become a place of truly shared sociality - rather than just proximity, individualised convenience, multiple forms of entertainment and, ultimately, full of surprise and ever present opportunities for discovery.

This paper contributes to existing smart city research on two levels. Firstly, it extends theory by drawing on Shapiro's (2006) proposition that it is extremely important to consider the integrative abilities of digital technologies, the theoretical proposition of "engagement' between technology, people and the city. The use of engagement theory illustrates that a deeper understanding about how to productively create smart cities that are socially inclusive is possible and useful. The paper has also drawn on theorists such as Herandez-Munoz et al. (2011) and Ackoff (1971) that recognise cities as "systems of systems" and therefore there cannot be a grand theory proposition that will provide an overarching solution for all smart city planning and development to create the smart city. Instead, we have presented a means to uncover the key issue for the operationalisation and planning process for particular communities associated with each smart city. It is inclusivity on the planning, operationalisation and ultimately development of a smart city and what is needed, is large-scale gathering of stakeholder opinions. A cross section of voices including those of individual and commercial stakeholders, government officials and policy makers are all needed to fully test attitudes to technology in the high street as well as to understand what forms of social engagement are wanted and desirable in the high street within the local context in these engagements. Research must set out to understand the differences of opinion, perspectives and the conflicting agendas of stakeholders and recognise how technology can enable satisfactory resolution - or at least compromise - to these issues through the application of sensible and sensitive policy-making.

\section{References}


Ackoff, M. (1971) 'Towards a System of Systems Concepts', Management Science, Vol. 17, No. 11 , pp. 661-671.

Association of Convenience Stores (ACS) (2013) 'Retail Planning Decisions under the NPPF Commisioned by the Asociation of Convenience Stores', http://towns.org.uk/files/retail_planning_decisions_final_report_dtp.pdf [Accessed 5 September 2014]

Babbie, E. (2010) The Practice of Social Research (12th edition) Wadsworth: Cengage learning.

Baldassare, M. (1992) 'Suburban Communities', Annual Review of Sociology, Volume. 18, p. 475-494.

Beiro, G. and Cabral, S. (2007) 'Understanding attitudes towards public transport and private car: A qualitative study', Transport Policy, Vol. 14, No. 6, pp. 478-489.

Bell, F. Fletcher, G. Greenhill, A. Griffiths, M. and McLean, R. (2013) 'Science fiction prototypes: Visionary technology narratives between futures' Futures, Vol. 50, pp. 5-14.

Berthon, P.R. et al. (2007) When customers get clever: managerial approaches to dealing with creative consumers. Business Horizons, Vol. 50, pp. 39-47.

Bititci, U., Turner, T., Mackay, D., Kearney, D., Parung, J. \& Walters, D. (2007) ‘Managing synergy in collaborative enterprises', Production Planning \& Control, Vol. 18, No. 6, September, pp. 454-465.

Blanco, E. and Fransoo, J. (2013) 'Reaching 50 million nanostores: Retail distribution in emerging megacities', BETA Research School, Eindhoven University of Technology, Working Paper Series No. 4, January.

Browne, M. and Gomez, M. (2011) 'The impact on urban distribution operations of upstream supply chain constraints', International Journal of Physical Distribution and Logistics Management, Vol. 41, No. 9, pp. 896-912.

Budweg, S. Schaffers, H. Ruland, R. Kristensen, K. Prinz, W. (2011) 'Enhancing collaboration in communities of professionals using a Living Lab approach' Production Planning \& Control: The Management of Operations. Vol. 22, No. 5-6, pp. 594-609.

Chaney, D. (1985) 'The Department Store as a Cultural Form', Theory, Culture \& Society, Vol. 1, No. 3, pp. 22-32.

Chaney, D. (1990) 'Subtopia in Gateshead: The MetroCentre as a Cultural Form', Theory, Culture \& Society, Vol. 7, pp. 49-68. 
Collis, C. Berkeley, N. and Fletcher, D. (2000) 'Retail Decline and Policy Responses in District Shopping Centres' Town Planning Review, Vol. 71, No. 2, pp. 149-168.

Copenhagen CleanTech Cluster (2012) 'Danish Smart Cities: Sustainable living in an urban world', J. Mortensen, F. Rohde, K. Kristiansen , M. Kanstrup-Clausen and M. Lubanski (eds.), Copenhagen Capacity: Copenhagen, http://www.cphcleantech.com/media/2021654/smart\%20city\%20rapport_indhold_final_low.pdf [Accessed 4 October 2014]

Crawford, J.H. (2005) 'A Brief History of Urban Form, Street Layout Through the Ages', http://www.carfree.com/papers/huf.html [Accessed 28 April 2015]

de Certeau, M. (1984) The Practice of Everyday Life, University of California Press: London.

Department for Communities and Local Government (2012) 'Portas Pilots to kick-start high street renaissance' https://www.gov.uk/government/news/portas-pilots-to-kick-start-high-streetrenaissance [Accessed 6 October 2014]

Department for Communities and Local Government (2013) 'The Future of High Streets: Progress since the Portas Review' https://www.gov.uk/government/uploads/system/uploads/attachment_data/file/211536/Future_of _High_Street_-_Progress_Since_the_Portas_Review_-revised.pdf [Accessed 7 October 2014]

Department for Communities and Local Government (2014) 'Ensuring the Vitality of Town Centres'. Planning Practice Guidance.

http://planningguidance.planningportal.gov.uk/blog/guidance/ensuring-the-vitality-of-towncentres/ensuring-the-vitality-of-town-centres-guidance/ [Accessed 3 October 2014]

Department for Transport (2011) 'New Guidance on the Design of Shared Space Streets' https://www.gov.uk/government/news/new-guidance-on-the-design-of-shared-space-streets [Accessed 6 October 2014]

Dimitriadis, N. \& Koh, S. (2005) 'Information flow and supply chain management in local production networks: the role of people and information systems', Production Planning \& Control, Vol. 16, 6, September, pp. 545-554.

Fletcher, G. Greenhill, A. Griffiths, M. McLean, R. (2013) 'The Social Supply Chain and the Future High Street' Supply Chain Management: An International Journal (Forthcoming).

Frick, E. Tardini, S. and Cantoni, L. (2013) White Paper on Lego Serious Play: A State of the Art of its Applications in Europe. Switzerland: Università della Svizzera Italiana, pp. 1-26.

Gauntlett, D. (2007) Creative Explorations: New Approaches to Identities and Audiences. London: Routledge. 
Gauntlett, D. and Holzwarth, P. (2006) 'Creative and visual methods for exploring identities'. Visual Studies, Vol. 21, No. 1. pp. 82-91

Global Connections (2013) 'Profiting from the Smart City Revolution' https://globalconnections.hsbc.com/canada/en/articles/profiting-smart-cities-revolution [Accessed 29 September 2014]

Goss, J. (1993) 'The 'Magic of the Mall': An analysis of form, function and meaning in the contemporary retail built environment', Annals of the Association of American Geographers, Vol. 83, No. 1, pp. 18-47.

Graham, G. (2014) 'Too-smart cities? Why these visions of utopia need an urgent reality check' The Guardian http://www.theguardian.com/cities/2014/mar/13/too-smart-cities-visions-utopiareality-check [Accessed 28 April 2014]

Hernandez-Munoz, J. Vercher, J. Munoz, L. Galache, J. Presser, M. Hernandez-Gomez, L. and Perttersson, J. (2011) 'Smart Cities at the Forefront of the Future Internet', in J. Deomnigue (ed.) Future Internet Assembly, Springer, pp. 447-462.

House of Commons, All-Party Parliamentary Small Shops Group (2006) 'High St Britain: 2015', London. APPSSG.

Hodgkinson, S. (2011) 'Is Your City Smart Enough? Digitally enabled cities and societies will enhance economic, social and environmental sustainability in the urban century'. Ovum http://www.cisco.com/web/strategy/docs/ls_your_city_smart_enough-

Ovum_Analyst_Insights.pdf [Accessed 28 April 2014]

Holt, D. (1995) 'How Consumers Consume: A Typology of Consumption Practices', Journal of Consumer Research, Vol. 22, June, pp. 1-16.

Holmes, K. McLean, R. and Green, G. (2012) 'Crafting a Future Online: A Study of How Independent Craftspeople Adopt Social Media and Web Technologies', Journal of Systems and Information Technology, Vol. 14 No. 2.

Jackson, C. and Watkins, C. (2011) 'Planning Policy and Retail Property Investment in the UK', Urban Studies, Vol. 48, No. 11, pp. 2321-2338.

Jones, C. (2010) 'The Rise and Fall of the High Street Shop as an Investment Class', Journal of Property Investment \& Finance, Vol. 28 Issue. 4, pp. 275-284.

Kohno, T. and Johnson, B. (2011) 'Science Fiction Prototyping and Security Education: Cultivating Contextual and Societal Thinking in Computer Security Education and Beyond', SIGCSE'11, March 9-12, Dallas, Texas, USA, 
https://homes.cs.washington.edu/ yoshi/papers/SIGCSE/csefp118-kohno.pdf [Accessed 7 October 2014]

Korten, D. (1996) 'Civic Engagement in Creating Future Cities' Environment and Urbanization, Vol. 8, No. 1, pp. 35-49.

van Laere, J. de Vreede, G. J. and \& Sol, G. (2006) 'A social simulation-game to explore future co-ordination in knowledge networks at the Amsterdam Police Force', Production Planning \& Control, Vol 17, No. 6, September, pp. 558-568

Laermans, R. (1993) 'Learning to Consume: Early Department Stores and the Shaping of the Modern Consumer Culture (1860-1914)', Theory, Culture \& Society, Vol. 10, pp. 79-102.

Langman, L. (1991) 'Alienation and Everyday Life: Goffman Meets Marx at the Shopping Mall', International Journal of Sociology and Social Work, Vol. 11, Issues. 6/7/8, pp.107-124.

Lewis, G. (1990) 'Community through exclusion and illusion: the creation of social worlds in an American shopping mall', Journal of Popular Culture, Vol. 24, No. 2, Fall, pp.121-136.

Lorch, B. and Smith, M. (1993) 'Pedestrian Movement and the Downtown Enclosed Shopping Center', APA Journal, Vol. 59, No. 1, pp. 75-86.

McCarthy, P. Silvestre, B. \& Kietzmann, J. (2013) 'Understanding Outsourcing Contexts through Information Asymmetry and Capability Fit', Production Planning \& Control, Vol. 24, 4-5, April, pp. 277-283.

Nam, T. and Pardo, T. (2011) 'Conceptualizing Smart City with Dimensions of Technology People and Institutions', Proceedings of 12th Annual International Digital Government Research Conference: Digital Government Innovation in Challenging Times. June 12-15, 2011, pp. 282291.

Pearson, R. (1993) 'Knowing one's place: perceptions of community in the industrial suburbs of Leeds, 1790-1890', Journal of Social History, Vol. 27, No. 2, pp. 221-244.

Peterson, T. (2007) 'Development of City Logistics Concept' Production, Planning and Control: The Management of Operations, Vol. 17, No. 6, pp. 616-623.

Pehlivan, Ekin, et al. (2013) "When outsourcing fragments: customer creativity and technological transmutations." Production Planning \& Control Vol. 24. No. 4-5 pp. 284-293.

Planning Aid England (2012) 'Good Practice Guide to Public Engagement in Development Schemes' http://www.rtpi.org.uk/media/6312/Good-Practice-Guide-to-Public-Engagement-inDevelopment-Scheme-High-Res.pdf [Accessed 30 September 2014] 
Portas, M. (2014) 'Why Our High Streets Still Matter: A Think Piece by Mary Portas' http://www.portasagency.com/wp-

content/uploads/2014/05/WhyOurHighStreetsStillMatter_MaryPortas.pdf [Accessed 7 October 2014]

Prus, R. and Dawson, L. (1991) 'Shop 'til you Drop: Shopping as Recreational and Labourious activity', Canadian Journal of Sociology, Vol. 16, No. 2, pp.145-164.

Rasmussen, R. (2006) 'When you Build in the World, You Build in Your Mind' Design Management Review, Vol. 17, No. 3, pp. 56-63.

Rasmussen Consulting (2012) The Science Behind the Serious Play Method http://seriousplayground.squarespace.com/storage/The\%20Science\%20Behind\%20the\%20LEG O\%20SERIOUS\%20PLAY\%20Method.pdf [Accessed 19 August 2014]

Rigby, D. (2011) 'The Future of Shopping', Harvard Business Review, December.

Roberts, N. (2013) 'Clicks versus Bricks: The Battle for the High Street', INSEAD Knowledge, http://knowledge.insead.edu/business-finance/marketing/clicks-versus-bricks-the-battle-for-thehigh-street-2442\#AtTqxx7zcG7ZexBL.99 [Accessed 7 October 2014]

Roos, J. Victor, B. and Statler, M. (2004) ‘Playing Seriously with Strategy’ Long Range Planning, Vol. 37, Issue, 6. pp. 549 - 568.

Sack, R. (1988) 'The Consumer's World: Place as Context', Annals of the Association of American Geographers, Vol. 78, No. 4, pp. 642-664.

Sarmah, S. (2014) 'America's Digital Divide: Startups Fly, Storefronts Struggle' http://www.builtinchicago.org/blog/americas-digital-divide-startups-fly-storefronts-strugglechicago [Accessed 24 November 2014]

Shapiro, J. (2006) 'Smart Cities: Quality of Life, Productivity and Growth Effects of Human Capital', The Review of Economies and Statistics. Vol. 88, No. 2, pp. 324-335.

The Telegraph (2011) 'Mary Portas: High streets destined to “'disappear forever"' http://www.telegraph.co.uk/finance/newsbysector/retailandconsumer/8951411/Mary-Portashigh-streets-destined-to-disappear-forever.html [Accessed 6 October 2014]

Temperton, J. (2015) 'Bristol is making a smart city for actual humans'. Wired http://www.wired.co.uk/news/archive/2015-03/17/bristol-smart-city [Accessed 20 May 2015]

Townsend, A. (2013) Smart City, Big Data; civic hackers, and the quest for a new utopia, Norton and Company: New York and London. 
Valentine, M. (2013) 'Analysis: Have the Portas Pilot towns succeeded?' Retail Week, http://www.retail-week.com/analysis-have-the-portas-pilot-towns-succeeded/5049908.article [Accessed 20 July 2014]

Vaughan, M. (1978) 'Multinational Corporations: The world as a company town', in Idris-Soven, A. (ed.), The World as a Company Town, Mouton Publishers: The Hague, pp.15-35.

Walsham, G. (1995), 'The Emergence of Interpretivism in IS Research', Information Systems Research, Vol. 6, No. 4, pp. 376 - 394.

White, D. and Hellerick, G. (1994) 'Nietzsche at the Mall: deconstructing the consumer', $C$ Theory, Vol. 17, No. 1/2, pp. 76-99.

Willis, J. (2007) Foundations of Qualitative Research: Interpretive and Critical Approaches, Sage Publications: London, UK, pp. 298 - 299.

Wrigley, N. and Lambiri, D. (2014) High Street Performance and Evolution; A Brief guide to the evidence, University of Southampton Economic, and Social Research (ESRC) http://thegreatbritishhighstreet.co.uk/pdf/GBHS-HighStreetReport.pdf [Accessed 28 September 2014]

Wood, Z. (2014) 'Independent retailers plug high street gaps left by chain store exodus'. The Guardian, http://www.theguardian.com/business/2014/mar/25/independent-shops-growth-chainstore-exodus-high-streets [Accessed 15 September 2014]

Wu, H. (2013) 'Imagination workshops: An empirical exploration of SFP for technology-based business innovation' Futures, Vol. 50, pp. 44-55.

\section{Appendix 1}

\begin{tabular}{|c|c|}
\hline Number & Participant description \\
\hline 1 & Consumer/customer \\
\hline 2 & Academic \\
\hline 3 & City Council employee \\
\hline 4 & Consumer/customer \\
\hline 5 & Retail owner \\
\hline 6 & Retail owner \\
\hline 7 & Community organisation representative \\
\hline
\end{tabular}




\begin{tabular}{|c|c|}
\hline 8 & Academic \\
\hline 9 & Retail owner \\
\hline 10 & Academic \\
\hline 11 & City council employee \\
\hline 12 & Technology evangelist \\
\hline 13 & Academic \\
\hline 14 & Community organisation representative \\
\hline 15 & Consumer/customer \\
\hline 16 & Consumer/customer \\
\hline 17 & City Council employee \\
\hline 18 & Community organisation representative \\
\hline
\end{tabular}

Table 3 - Summary of participants in attendance 